\title{
The effect of ginger on testis of Broiler breeders
}

\author{
Mansour Hamzehnezhad ${ }^{a}$, Hossein Erik-Aghaji ${ }^{b}$, Afshin Zakeric, Sajjad Hejazi ${ }^{\text {d* }}$
}

\begin{abstract}
The rhizome of ginger is a fresh or dried organ of the plant Zingiber officinale, which has been used as a medicine since ancient times. The present study was conducted to examine the effects of ginger on testicular histomorphometry in roosters of broiler chicken flocks. Eighty single-day rooster of broiler chickens belonging to 308 Ross breed was used in the present study. The chickens were divided into two groups with 40 broiler roosters (experimental and control groups). Initially, the rhizome of ginger was powdered; $1 \mathrm{~g} / \mathrm{kg}$ of ginger powder was added to the ration of the group treated with ginger from the beginning of the breeding season. The blood samples were taken from each chick at 20 weeks of age. The samples were stained with H\&E. Data was expressed as mean \pm SD. T-test was used to analyse and compare the difference between the control is also an experimental groups using SPSS 9.0 software. The testosterone level, weight of the testicle, thickness of seminal tube and number of spermatids in the experimental group compared to the control group increased significantly $P<0.05$. The most important difference between the control and the intervention group treated with ginger was the number and density of spermatids and spermatozoids cells in the lumen area of the seminal tubes. The present study obtained positive results for the efficacy of using ginger in roosters of broiler chick flocks.

Key words: ginger, histomorphometry, roosters, testis, testosterone.
\end{abstract}

\section{INTRODUCTION}

Promoting fertility indices is of particular importance in poultry industry, and there are always numerous studies being conducted on the principles of management and nutrition in order to achieve the highest quality. Nowadays, extensive research is being conducted on using medicinal plants in the field of sexual disability treatment; according to books on traditional medication, it is possible to increase fertility and eliminate such issues as hormonal imbalance, sexual disability (sexual dysfunction), low sperm count, sperm motility, prostate inflammation, and varicocele through using medicinal plants (Ebisch et al 2007). The rhizome of ginger is a fresh or dried organ of the plant Zingiber officinale, which has been used as a medicine since ancient times. This plant populates a large area, from East Asia to tropical Australia. The most important compounds of ginger are shogoals, gingerols, ginkels, jranil, gingerols, pyrogallols, and zinjiburon (Bhattaria et al 2001 and Gupta et al 2001). Regarding the anti-inflammatory effects of this plant, numerous reports have indicated that the active compounds of this plant, namely gingerols, shogoals and curcumin, have the potential to inhibit the production of prostaglandins, nitric oxide and even the interleukins involved in inflammation. The ginger and its compounds have been shown to have

Received: 10.07.2018.

Accepted: 29.11.2018.

${ }^{a}$ Faculty of Veterinary Medicine, Tabriz Branch, Islamic Azad University, Tabriz, Iran

${ }^{b}$ Faculty of Specialized Veterinary Sciences, Science and Resarch Branch, Islamic Azad University, Tehran, Iran.

'Department of Animal Science, Tabriz Branch, Islamic Azad University, Tabriz, Iran.

${ }^{\mathrm{d} D e p a r t m e n t ~ o f ~ C o m p a r a t i v e ~ A n a t o m y, ~ F a c u l t y ~ o f ~ V e t e r i n a r y ~ M e d i c i n e, ~}$ Tabriz Branch, Islamic Azad University, Tabriz, Iran.

*Corresponding author: S Hejazi; sajjadhejazi1@gmail.com anti-vomiting, anti-thrombosis, liver, and anti-inflammatory properties. It also has antioxidant and androgenic activities. Due to the antioxidant nature of ginger, it has a desirable effect on sperm incompatibility treatment and poor sperm function (Garolla et al (2005). Additionally, and more specifically, the enzymes producing these substances as inflammatory mediators are inhibited by the active ingredients of ginger, which is one of the main components of these compounds and has antioxidant and antibacterial properties. It has been reported that gingerols, shogoals, and zinjiburon compounds of ginger have antioxidant properties (Dalia 2010). The effects of ginger on the body include the removal of free radicals (Altman and Marcussen 2001), spermatogenesis (Mir heydar et al 1996) and increasing sexual desire (Zargari 1999). It has also been reported that testosterone is needed to maintain the spermatogonia and inhibit sperm cell apoptosis ${ }^{1}$. Research has shown that ginger has beneficial compounds that are of great help in sperm production. Therefore, lack of these compounds can lead to malformation of the cell membrane (Sharma et al 1996). Research has also shown that in chickens taking $100 \mathrm{mg}$ ginger daily for one month increases sperm parameters, testicular antioxidant enzymes, and testosterone levels (Koracevic et al 2001). Therefore, the present study was conducted to examine the effects of ginger on testicular histomorphometry in roosters of broiler breeder.

\section{MATERIAL AND METHODS}

Eighty single-day rooster of broiler chickens belonging to 308 Ross breed was used in the present study. To this end, a broiler farm in the private sector located in the city

\footnotetext{
Tanis D, Orrell D, Long DW. 2010. The effects of a dietary supplement, free test, on serum free and total testosterone levels in weight-trained male subjects. Applied Nutriceuticals, North Carolina, USA.
} 
of Tabriz was used, a farm which was quite homogenous in terms of geographical and environmental conditions. The room was disinfected after being washed with high pressure water. All the chambers, doors, and windows were covered, and finally the saloon was charged with formaldehyde gas to zero the microbial load of the environment. The temperature of the room was about $32{ }^{\circ} \mathrm{C}$ during the first day, decreasing by one degree for every three days until it reached $21^{\circ} \mathrm{C}$ at the $27^{\text {th }}$ day of the breeding season, and this degree remained constant for all groups until the end of the breeding season. A mixture of natural daylight and artificial lighting was used to provide the required lighting in the present study. All chickens were fed in the same way in terms of the components of the dietary formula and their dosages (table 1). The diet of the chicks consisted of the same components used in the current approach of the majority of countries in order to achieve the highest possible practicality and use for the present research. The lighting program was regulated at 10-15 lux with 12-17 hours duration per day. The study complies with

Table 1. Control basal - diet fed to broiler breeder rooster (NRC 1994).

\begin{tabular}{lr}
\hline Ingredients (\%) & Roosters \\
\hline Maize & 66.00 \\
Soybean meal (44\% CP) & 11.0 \\
Wheat bran & 18.37 \\
Vitamin-Mineral mix & 0.5 \\
Calcium carbonate & 1.5 \\
Oysters shell & 0.5 \\
Dicakium phosphate & 1.4 \\
DL-methionine & 0.08 \\
L-lysine HCL & 0.07 \\
Salt & 0.2 \\
Sodium bicarbonate & 0.15 \\
Natuzyme-P* & 0.03 \\
Toxin binder* & 0.1 \\
Formycine Cold* & 0.1 \\
& \\
Nutritional analysis & 2700 \\
ME, kcal kg & \\
Crude protein (\%) & 13.5 \\
Calcium (\%) & 1.1 \\
Available Phosphorus (\%) & 0.4 \\
Sodium (\%) & 0.16 \\
Chloride (\%) & 0.18 \\
Lysine (\%) & 0.6 \\
Methionine (\%) & 0.3 \\
Ether extract (\%) & 3.15 \\
Fibre (\%) & 4.2 \\
Linoleic acid (\%) & 1.80 \\
\hline
\end{tabular}

*Natuzyme-p, containing phytase: 1,000,000 U/g. B glucanse: 700U/g, $\alpha$-amylase: $700 \mathrm{U} / \mathrm{g}$, cellulose: $6000 \mathrm{U} / \mathrm{g}$, pectinase: $700 \mathrm{U} / \mathrm{g}$, xylanse: $10.000 \mathrm{U} / \mathrm{g}$, lipase: $30 \mathrm{U} / \mathrm{g}$, and protease: $3000 \mathrm{U} / \mathrm{g}$, Toxin binder contains natural hydrated sodium calcium aluminium silicats; Formycine Gold is a broad spectrum disinfectat feed additive that includes ammonia, formaldehyde, propionic acid and sodium bentonite. The basal - diet (control) supplied per kg: $3 \mathrm{mg}$ of vitamin A and $37 \mathrm{mg}$ of vitamin E. the notification protocol of the Islamic Republic of Iran Veterinary Office and the changes required by the geographical area of the breeding farms.

\section{IMPLEMENTATION OF THE TREATMENT}

Initially, the rhizome of ginger was powdered; $1 \mathrm{~g} / \mathrm{kg}$ of ginger powder $(0.1 \%$ of the base rations) was added to the ration of the group treated with ginger from the beginning of the breeding season. The total period of ginger treatment was 16 weeks. A total number of 80 single day the chickens (308 Ross Breed) were raised to 20 weeks of age. They were then examined and tested. Blood samples of 1-2 ml were taken from each chicken. The blood samples were then referred to a specialized poultry laboratory for testing.

Blood samples were taken from the vein underneath the wings of the chicks at the end of 20th week before the slaughter to measure the blood testosterone concentration. The serum of blood samples was separated and centrifuged at $1372 \mathrm{~g}$-force for 15 minutes. The separated serum was transferred into $2 \mathrm{~mm}$ microtubes by a sampler. Microtubes were immediately transferred to a freezer $\left(20 \pm 2{ }^{\circ} \mathrm{C}\right)$ and kept there until required experiments were carried out. The chickens blood serum samples were tested by ELISA (ELx808 ${ }^{\mathrm{TM}}$, Absorbance Reader, BioTek, USA) and serum testosterone levels were measured by RIA kits (Immunotech, Marseille, France).The testicles were fully removed from the body and weighed with a highly sensitive digital scale after abdominal dissection. The testicles were then placed in dishes containing formalin fixer to prepare the tissue removal process. The samples were put in a $10 \%$ buffer formalin solution, and $6-\mu \mathrm{m}$ thick paraffin blocks were stained with the general method of hematoxylin and Eosin (H\&E) stain after passing the autotechnicom steps (Bancroft and Gamble 2008). Histomorphometry variables of the weight of the testicle, thickness of seminal tube and the number of spermatids with the same cross-section were measured underneath a Nikon optical microscope made in Japan (Model: E200 Eclipse, Eye lens: 10X - 20mm, Magnification: 8 unit-1500 unit) having a linear gradient and a $40 \times$ lens. Spermatozoid density was comparatively calculated in each slide, which is quite clear in photomicrographs. A Nikon camera microscope manufactured in Japan (5-megapixel color CCD) was then used to prepare the corresponding Konica photomicrograph micrograph, and the obtained results were used for statistical analysis.

\section{STATISTICAL ANALYSIS}

Data was expressed as mean \pm SD. T-test was used to analyze and compare the difference between the control and treatment groups using SPSS 9.0 (SPSS Inc, Chicago IL, USA). 


\section{RESULTS}

The obtained mean level of testosterone hormone in the treatment group increased significantly as a result of using ginger in comparison with the control group at the level of $P<0.05$ (table 2). According to table 3, the obtained mean level of testis weight to the body significantly increased with ginger in the treatment group compared with the control group at the level of $P<0.05$ (table 3). The obtained mean level of the thickness of seminal tube significantly increased with ginger in the treatment group compared with the control group at the level of $P<0.05$ (table 3). The obtained mean weight of the testicle significantly increased with ginger in the treatment group compared with the control group at the level of $P<0.05$ (table 3). The obtained mean number of spermatids significantly increased with ginger in the treatment group compared with the control group at the level of $P<0.05$ (table 3). Photomicrographs 1-6 also indicate that the lumen of control group chicks is almost empty of spermatozoids and the number of spermatozoa has significantly increased in the lumen of chicks treated with ginger.

In the observations of testicular tissue at the age of 20 weeks, high density of generic cells was observed in epithelium and lumen space of seminal tubes. The development of blood vessels was more significant at this age and the interstitial spaces of the vessels of the group treated with ginger turned out to be both sharper and thicker in comparison with the control group (figures $1 \mathrm{~A}$ and $1 \mathrm{~B}$ ). The most important change observed in the testicles of the poultry at the age of 20 weeks was the presence of spherical and spatial nuclear spermatocyte cells in the internal part of the epithelium. Also, spermatozoids were observed in the luminal space of seminal tubes. Unlike mammals, these cells were stretched and bent, and long tails were seen. In chicks with 20 weeks of age, generic cells were observed all through the seminal tube. The most important difference between groups was the number and density of spermatozoids cells in the lumen area of the seminal tubes at treatment group than control group (Figures 1C and 1D). The significance of this difference is presented in table 3 .

\section{DISCUSSION}

Khaki et al (2008) reported that ginger extract increases the level of testosterone and the weight of testicles. The results of Johari et al (2009) indicated that the weight of testes increases along with the increase of ginger dose in the test group. The concentration of testosterone in the group treated with ginger increases. Testosterone stimulates the spermatogenesis and divides the FSH by cooperating with the hormone of the spermatogonia cells. Shogaols and gingerols are irritant androgens and have the potential to increase testicular weight and increase testosterone hormone. Morakinyo et al (2008) indicated that ginger extract inhibited the production of released radicals and reduced lipid peroxidation significantly by maintaining antioxidant activity of superoxide dismutase enzymes, catalase and glutathione peroxidase. It also increased the number of sperms in comparison with the control group. Shariatzadeh et al (2016) reported to compare the levels of testosterone in different groups. Bordbar et al (2013) indicated that ginger extract increased the volume of seminal tubes, the number of sperms and the level of testosterone in the infertile mice. Ginger plant seems to stimulate reproduction, following the induction of infertility by the Busulfan drug. Khaki et al (2008) reported

Table 2. The comparison of mean biochemical parameter obtained from testis of control group and treatment group receiving ginger ${ }^{*}$ $(n=20)$.

\begin{tabular}{lcc}
\hline Parameter & Control group & Treatment group \\
\hline Testosterone level $(\mathrm{Ng} / \mathrm{ml})$ & $3.644 \pm 0.89 \mathrm{a}$ & $5.930 \pm 0.331 \mathrm{~b}$ \\
\hline
\end{tabular}

*Values are means \pm SD.

Different literals in the same row indicate statistical difference $(P<0.05)$

Table 3. The comparison of mean morphometric parameters obtained from testis of control group and treatment group receiving ginger* $(n=20)$.

\begin{tabular}{lcc}
\hline Parameteres & Control group & Treatment group \\
\hline Testicle weight $(\mathrm{gr})$ & $230 / 83 \pm 0 / 413^{\mathrm{a}}$ & $303 / 53 \pm 33 / 33^{\mathrm{b}}$ \\
Thickness of seminal tube $(\mu \mathrm{m})$ & $17.74 \pm 0.383^{\mathrm{a}}$ & $21.3 \pm 0.263^{\mathrm{b}}$ \\
Number of spermatozoids & $123.4 \pm 11.07^{\mathrm{a}}$ & $158.2 \pm 4.24^{\mathrm{b}}$ \\
\hline
\end{tabular}

*Values are means \pm SD.

Different literals in the same row indicate statistical difference $(P<0.05)$. 

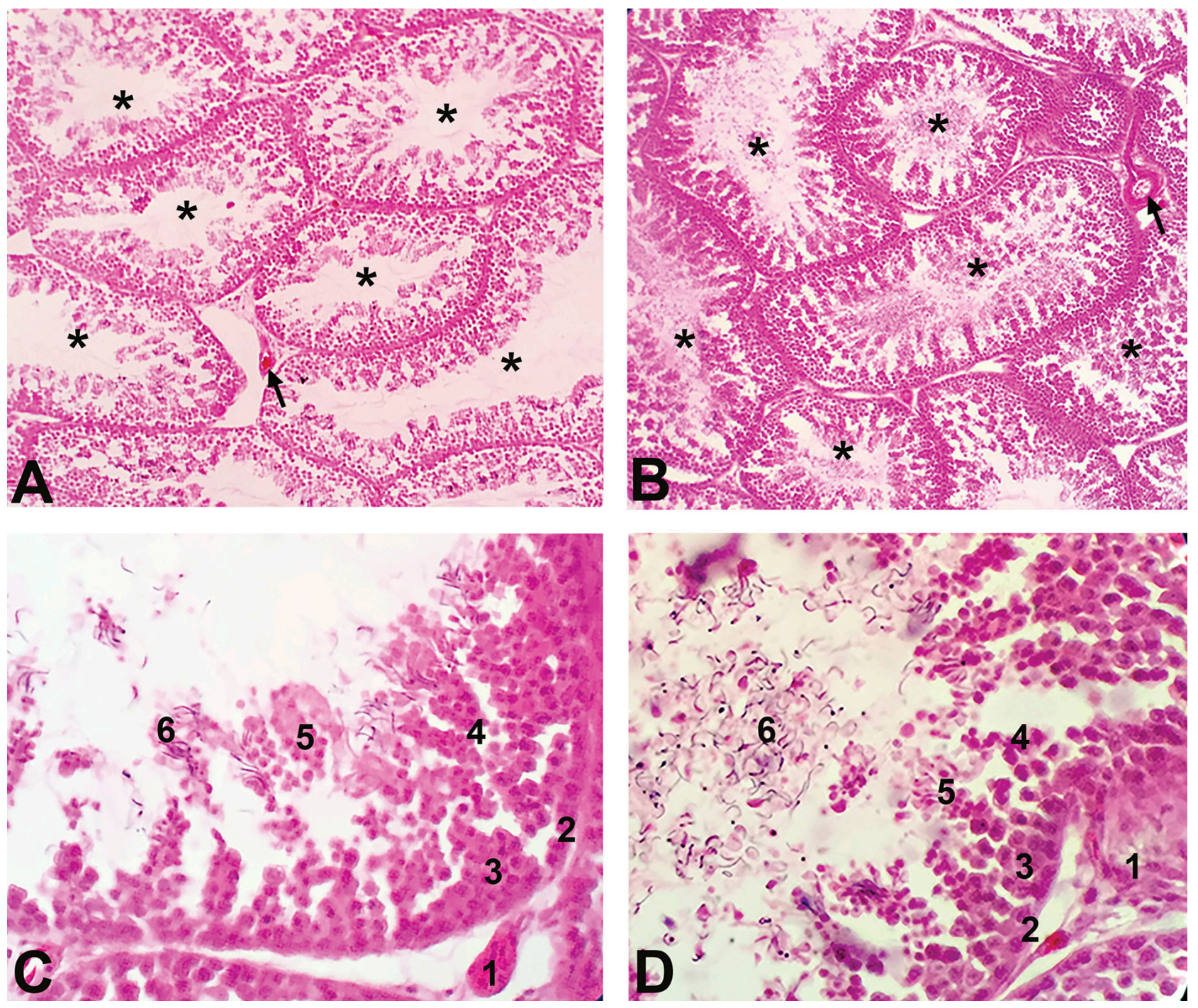

Figure 1. Histological structure of the testis of broiler chiken. A) Normal group B) Treatment group. Seminiferous tubule (star), Capillary (arrow) (H\&E sainting, 10×). C) Normal group D) Treatment group. 1: Leydig cell; 2: spermatogonium; 3: primary spermatocyte; 4: secondry spermatocyte; 5: spermatid; 6: spermatozoid (H\&E sainting, 100x).

that using $100 \mathrm{mg}$ of ginger brings about a significant increase in the viability of sperm. Khani et al (2012) argued that using ginger in the ration of poultry increases the serum levels of superoxide dismutase enzymes, catalase, and glutathione peroxidase, which are considered to be important antioxidant enzymes. There was a significant difference, indicating the efficacy of ginger on testicular tissue, between the control and treatment groups of the present study in terms of the number of spermatids and spermatozoids at 20 weeks of age. According to the results of the testosterone test, there was a significant difference between the control and treatment groups in terms of blood contents, indicating the efficacy of ginger in increasing the level of testosterone. The findings of the present study are consistent with the results of Khaki et al (2008), Bordbar et al (2013), Shariatzadeh et al (2016) and Johari et al (2009). Also, the results of this study showed an increase in testicular weight, which is consistent with the results of Johari et al (2009) and Khaki et al (2008). There was also a significant difference between the two groups in terms of the number of spermatozoa cells. This points to the effect of ginger on increasing testosterone and spermatogenesis in testicular tissue. There was also a significant difference between the two groups in the present study in terms of the number of spermatozoids in the lumen space. The number of spermatozoids is related to the spermatogenesis process, which is also influenced by the testosterone hormone. It can be concluded that the effects of ginger include increased testosterone, which accelerates and activates the process of spermatogenesis in the testes, which is consistent with the results of Morakinyo et al (2008) and Bordbar et al (2013). Increased diameter of the vessels in the testicular interstitial space in the ginger group is one of the main differences between 
the two groups in terms of changes in the structure of the tissue. Increased diameter of the vessels increases and accelerates blood flow and the level of testosterone hormone, which results in improved spermatogenesis in the testicle and, finally, increased fertility.

The positive results using ginger in roosters of broiler chick flocks found in the present study can have significant value in the economic cycle of poultry industry, including agricultural industry, veterinary administration, colleges, meat industry, and industries related to the processing of meat products, since fertility is one of the most important factors in poultry industry and huge costs are paid annually to improve the quality and quantity of fertility.

\section{ACKNOWLEDGEMENTS}

This article is derived from a doctoral thesis approved by Department of basic sciences, Tabriz branch, Islamic Azad University, Tabriz, Iran.

\section{REFERENCES}

Altman RD, Marcussen KC. 2001. Effects of a ginger extract on knee pain in patients with osteoarthritis. Arthritis Rheum 44, 2531-2538.

Bancroft JD, Gamble M. 2008: Theory and practice in histological techniques. $6^{\text {th }}$ ed. Churchill Livingstone, Edinburgh, UK.

Bhattaria S, Tran VH, Duke CC. 2001. The stability of gingerol and shogaol in aqueous solutions. J Pharm Sci 90, 1658-1664.

Bordbar H, Esmaeilpour T, Dehghani F, Panjehshahin MR. 2013. Stereological study of the effect of gingers alcoholic extract on the testis in busulfan - induced infertility in rats. Int J Reprod Biomed 11, 267-272.

Dalia AH. 2010. Effect of extracts of ginger roots and cinnamon bark on fertility of male diabetic rats Rats. J Am Sci 6, 940 - 947.
Ebisch IM, Thomas CM, Petres WH, Braat DD, Steegers RP, et al. 2007. The importance of folate, zinc and antioxidants in the pathogenesis and prevention of subfertility. J Hum Reprod Update 13, 163-74.

Garollia A, Maiorino M, Roverato A, Roveri, F, Ursini A, et al. 2005. Oral carnitine supplementatiom increases spermmotility in asthenozoospermic men with normal sperm phospholipid hydroperxide glutathione peroxidase levels. Fertil Ste 83, 355-361.

Gupta YK, Sharma M. 2001. Reversal of pyrogallol-induced delay in gastric empting in rats by ginger (Zingiber officinale) Methods Find. Exp Cline Pharmacol 23, 501-503.

Johari H, Sharifi E, Ansari N, Hosseini M, Amiri F. 2010. Effect of hydro alcoholic ginger extracts on the body weight, testis weight and spermatogenesis in male rats undergoing chemotherapy with cyclophosphamide. JSSU 17, 365-374.

Khaki A, Nouri M, Fathiazad F, Khaki A. 2008. Evaluation of Zingiber officinalis and Allium cepa on spermatogenesis in rat. Med J Tabriz Uni Med Sci 30, 53-58.

Khan RU, Naz S, Nikousefat Z, Tufarelli V, Javdani M, et al. 2012. Potential applications of ginger (Zingiber officinale) in poultry diets. World Poult Sci J 68, 245-252.

Koracevic D, Koracevic G, Djordjevic V, Andrejevic S, Cosic V. 2001. Method for the measurement of antioxidant activity in human fluids. J Clin Pathol 54, 356-361.

Mir Heydar H. 1996. Herbal application in preventing and treatment of disease. Islamic Emission Bureau. Tehran, Iran.

Morakinyo AO, Adeniyi OS, Arikawe AP. 2008. Effects of Zingiber officinale on reproductive functions in the male rat. Afr J Biomed Res 11, 329-334.

NRC, National Research Council. 1994. Nutrient requirements of poultry. $9^{\text {th }}$ ed. National Academic Press, Washington, USA.

Shariatzadeh S, Hasanvand A, Fallah-huseini H. 2016. The protective effect of ginger extract against bisphenol-A induced testicular toxicity in NMRI Mice. Journal of Medicinal Plants 2, 151-163.

Sharma PK, Agarwal A. 1996. A role of reactive oxygen species in male infertility. Urology 48, 835-850.

Zargari A. 1996. Medicinal plants. Vol 3. Tehran University Publications, Tehran, Iran. 
